\title{
Toward a (Smart) Service science
}

\author{
Marco De Marco ${ }^{1}$, Eleonora Veglianti ${ }^{2}$ \\ ${ }^{1}$ Department of Economics, University of Uninettuno, 00186 Rome, Italy. \\ ${ }^{2}$ FGES- Université Catholique de Lille, 59800 Lille, France.
}

The COVID-19 widespread represents a breaking point for several disciplines and it requires a rethought of various elements that in the pre-pandemic were considered well defined standards.

Thus, the current pandemic emergency opens new fields of discussion which need further scientific investigations. The virus circulates overcoming national borders with its victims having a heterogeneous trend that impacts business sectors and activities from many perspectives.

Now, more than ever, also the service sectors should rethink some concepts and features toward a (smart) required approach. The COVID-19 enhances a compulsory evolution that also hits the service science side.

Traditionally speaking, the service sector was largely identified among the more industrialized economies [1]. However, recently is becoming a worldwide phenomenon and several initiatives come out especially in terms of service systems and networks [2].

In other words, the growth of the service sector is unique in human history considering the global economy [3]. Thus, its future development is a topic of great interest in the academic as well as in the practitioner's community. Moreover, also due to the pandemic emergency, the role of service innovations is critical in different contexts to improve economic growth.

In this scenario, service science scholars have to start from the dawn laying the groundwork of the main elements of its theoretical background to clearly highlight what to do next.

Therefore, what is service science?

Service science is defined as an integration of various disciplines such as management, engineering, accounting, finance and operations [4]. This discipline wants to explain and improve interactions where different entities plays together to reach an outcome with an overall benefit [1].

In other terms, the multidisciplinary approach of service science captures increasingly the interest among scholars, practitioners as well as governments.

For instance, several academic and not only $[3,5,6,7]$ show the importance of this field of research in their scientific contributions consistent with a value co-creation purpose.

The multidisciplinary feature of service science defines many important interpretations and initiatives that reach and impact the academic and professional audience.

However, what does it mean exactly?

On the one hand, service science focuses on services that are value-cocreation driven by a number of knowledge-intensive interactions. 
On the other hand, science is the sample of methods, theories, models and features that the scientific community use to build further knowledge on a specific phenomenon [9]. Thus, service science wants to spread new knowledge, methods and theories that consider the value-cocreation between interacting entities.

Furthermore, in this research setting, another fundamental aspect is related to service systems which are dynamic configurations of various elements such as people, technologies, organizations and information that create value to stakeholders [4].

In addition, innovation gained a critical role as it implies the birth of new ideas and/or methods from the combination of creativity and implementation [9].

As noted, in this scientific area, innovation affects the service system in terms of possible changes and further developments [10].

Today, more than in the past, given the above and the uniqueness of our current era which is driven by a strong digital transformation and a peculiar pandemic situation, it is necessary to merge all these concepts. However, without forgiving that service depends on individuals - human-centered-ness [11] - as the relevant literature called.

Therefore, a crucial challenge emerges: to be more systematic about innovating in service with a constant coordination among people and technologies.

Following this perspective, it is confirmed again that service science results a specialization of systems science that needs more investigations studying the link between information systems and services [12].

In other words, information systems represent a vital element in many services and, as suggested, a required priority should be given to this research sphere [13].

Consequently, in the last decade the number of papers and contributions dedicated to this aspect is progressively flourished (i.e. [14]). Nevertheless, the significant literature is still constrained in silos with a focus, for instance, on specific features of the service sphere or on particular elements of the Information and Communication Technology (ICT) agenda. The latter is a decisive argument in the service science discipline taking into account its aim of being a multidisciplinary field.

Given that, what will be next?

Even now, the researchers are fragmented; this requires a discussion to avoid compartmentalized initiatives and findings. Each scholar needs to push the debate toward an interdisciplinary approach that appear to be the right direction of the service science, especially, as suggested, to develop a scientific foundation for systematic service innovation [15].

This is the future goal of service science with a world deeply influenced by service systems, data and technology. Hence, in this context, innovation means to better investigate about data and technology in service [11].

In line with this, the COVID-19 represents an opportunity as well as a challenge to rethink the service science discipline and to overthrow the barriers and constrains with the purpose of enhancing its multidisciplinary.

For instance, the popular topic regarding the remote or smart working that allow people, during the pandemic, to continue working from home in several sectors at global level pushed the interest on asleep topic.

Smart working shows that some sectors, having a previous technological knowledge, were already prepared to manage their workforce far from the offices in an imaginable scale and in a sustainable and conformable way.

Some sectors were well equipped in terms of technology other less; however, the COVID-19 opens the discussion about the role of ICT in some service sectors to make the relations with the working force better and safer as well as to make the work setting more portable and ubiquitous [16]. 
Such health COVID-19 emergency disrupts the traditional methods requiring an overall reorganization of the known business models to adapt the organizations to the incremental change.

In fact, the expansion of ICT applications goes in different fields and directions. The latter will reconfigure the structure of several sectors in the next future. As for example, there is the justice sector. Hence, technology has had a relevant influence on many social domains giving new opportunities and challenges also in terms of e-justice.

In other words, the current era characterized by the usage of ICT in many sectors can influence also the present and close future of the Court System. This will modify the experience and best practices concerning the assistance of the justice system. Moreover, studying this can provide a full improvement in public safety that creates an important scientific discussion ground in this field of research.

In the nowadays context, an overall replanning of established rules and features do not concern only specific sectors, companies, firms or organizations; but it results necessary for the whole society.

An interesting case is the worldwide implementation and development of the so-called smart cities. This can have significant outcomes in the traditional methods and theories that required academic attention. This kind of cities can demand new addresses and innovative proposals from a technological side as well as from a managerial or engineering side.

In other terms, smart cities are changing our point of view on city management and related services. In this scenario, service science can provide new inputs that can improve our knowledge to create additional value among all the entities involved in this influential phenomenon.

Therefore, technology is going to be much more powerful. It enables the support of service interactions and operations as well as it improves the usage of data. That is the case of open data platform, for instance, that are used by people not in the public sector with new insights and useful findings for the global community.

This highlights a historical change in the interaction between the public and individual side (i.e. $[17,18]$ ). Thus, open data replaces processes in various organizations with the purpose of delivering more innovative answers [19, 20].

These are some of the examples that show the need for a more holistic approach. During and after the COVID-19 pandemic, we require innovative ideas for resilient and sustainable progression of a high number of services which assist the human being progression.

The concept of being smart which is linked increasingly more to our society and to its different and divergent components result in a deep rethinking about traditional elements that impact also the service science toward being smarter and smarter. 


\section{References}

[1] J. Spohrer, S.L.Vargo, N. Caswell N, P.P. Maglio, The service system is the basic abstraction of service science. In: Proceedings of the 41st annual Hawaii international conference on system sciences (2008)

[2] IfM and IBM, Succeeding through Service Innovation: A Service Perspective for Education, Research, Business and Government. (Cambridge, United Kingdom, 2008)

[3] H. Chesbrough, J. Spohrer, A research manifesto for services science, Commun. ACM, 49(7), 35-40 (2006).

[4] I. Ng, R. Maull, L. Smith, Embedding the new discipline of service science, (Springer, Boston, MA, 2011) $13-35$

[5] IBM, Services Sciences: A new academic discipline http://almaden.ibm.com/asr/SSME/facsummit.pdf (2005)

[6] P.P. Maglio, S.Srinivasan, J. T. Kreulen, J. Spohrer, Service systems, service scientists, SSME, and innovation. Communications of the ACM, 49(7), 81-85 (2006)

[7] J. Spohrer, P.P. Maglio, The emergence of service science: Toward systematic service innovations to accelerate co-creation of value. Prod. and Oper. Manag., 17(3), 1-9 (2008).

[8] T. S. Kuhn, The structure of scientific revolutions (The University of Chicago Press, 1962).

[9] K. A. Lyons, Service Science in iSchools, https://www.ideals.illinois.edu/handle/2142/14946 (2010)

[10] J. Tidd, F. M. Hull, Service innovation: Organizational responses to technological opportunities and market imperatives (Imperial College Press, London, 2003).

[11] P.P. Maglio, Editorial - Smart Service Systems, Human-Centered Service Systems, and the Mission of Service Science, J. Serv. Scien., 7(2) (2015)

[12] A. Rai, V. Sambamurthy, Editorial Notes-The Growth of Interest in Services Management: Opportunities for Information Systems Scholars, JSTOR, INFORMS 17(4) (2006)

[13] A.L. Ostrom, M.J. Bitner, S.W. Brown, A.K. Burkhard, M. Goul, S.D. Vicki, D. Haluk, E. Rabinovich Moving Forward and Making a Difference: Research Priorities for the Science of Service, J. Serv. Reser. 13(1), 4-36 (2010)

[14] M. Huang, Ming-hui, R.T. Rust, IT-related service: a multidisciplinary perspective, J. Serv. Reser., 16(3), 251-258 (2013)

[15] P.P. Maglio, C. Breidbach, A Service Science Perspective on the Role of ICT in Service Innovation Conference: European Conference on Information Systems (ECIS) (2015)

[16] Y. Yoo, O. Henfridsson, K. Lyytinen, The New Organizing Logic of Digital Innovation: An Agenda for Information Systems Research, J. INFORMS, 21(4), 724-735 (2010)

[17] L. Joo-Hyoung, K. Sun-Bae, A Desirable Corporate Culture under Smart Work Environment, J. Dig. Conv., 10(11), 93-102 (2012)

[18] K.Chudoba, E. Wynn, M. Lu, M. B. Watson-Manheim How virtual are we? Measuring virtuality in a global organization, J. Inf. Syst., 15(4), 279-306 (2005)

[19] B. Vilhemson, E. Thulin, What did we do when the Internet wasn't around? Variation in free-time activities among three young-adult cohorts from 1990/1991, 2000/2001, and 2010/2011, J. SAGE, 31(1),77-96 (2017)

[20] C. Ruiller, M. Dumas, F. Chédotel How to maintain the feeling of proximity at a distance? The case of teams dispersed by teleworking, J. RIMHE, 27(3), 3-28 (2017) 